\title{
Trillium Flap for Postmastectomy Neo-Nipple Reconstruction (A Novel Technique)
}

\author{
Ahmed Abdelmoez Alsayed \\ Independent Researcher, Al-Hokail, Khobar, Saudi Arabia \\ Email: az971986@gmail.com
}

How to cite this paper: Alsayed, A.A. (2020) Trillium Flap for Postmastectomy Neo-Nipple Reconstruction (A Novel Technique). Modern Plastic Surgery, 10, 9-16. https://doi.org/10.4236/mps.2020.101002

Received: November 26, 2019

Accepted: December 21, 2019

Published: December 24, 2019

Copyright $\odot 2020$ by author(s) and Scientific Research Publishing Inc. This work is licensed under the Creative Commons Attribution International License (CC BY 4.0).

http://creativecommons.org/licenses/by/4.0/

(c) (i) Open Access

\begin{abstract}
Introduction: Breast cancer cases, mastectomy and following reconstruction procedures are growing in numbers. Despite being lifesaving, mastectomies have a destructive psychological impact on the patients. On the other hand, breast reconstruction improves psychological damages within the same population. Various techniques for nipple reconstruction were described in literature. Trillium flap is an innovative technique to reconstruct neo-nipple with several advantages that make it superior to other popular flaps. Objectives: To come up with an innovative design for reconstructing a neo-nipple post mastectomy, that is superior to other popular flaps. Results: The Trillium flap design has less visible and easily camouflaged scars, is geometry-based, specific, well-detailed and flexible to produce a tailored nipple with any desired height and diameter and ensures the flaps good vascularity and the neo-nipple projection sustainability. Conclusion: Trillium flap is an innovative technique to reconstruct neo-nipple with several advantages that make it superior to other popular flaps. The results shown in the study are for experimental procedures done on human tissue samples of excised flaps from abdominoplasties and brachioplasties. Further application on actual cases is needed with monitoring of neo-nipple projection sustainability on the long term.
\end{abstract}

\section{Keywords}

Trillium, Flap, Breast, Nipple, NAC, Reconstruction, Neo-Nipple, Mastectomy

\section{Introduction}

It is estimated that there are more than 3.8 million women living in the United States with a history of invasive breast cancer, and 268,600 women will be newly diagnosed in 2019. More than 150,000 breast cancer survivors are living with 
metastatic disease, three-quarters of whom were originally diagnosed with stage I through III cancer [1].

Mastectomy is done for $34 \%$ of patients with early-stage (stage I or II) breast cancer, more than two-thirds (68\%) of patients with stage III disease and only $12 \%$ of patients with stage IV [2] (Figure 1).

Being diagnosed with breast cancer and undergoing mastectomy lead to serious psychological issues regarding self-esteem, self-consciousness and sexual intimacy suggesting the need for cognitive interventions [3] [4] [5] [6] [7]. On the other hand, breast reconstruction was found to have a benefit for improving the psychological damages in patients with breast cancer [8] [9].

There are various reports of nipple areola complex (NAC) reconstruction with flaps in the medical literature [10]. Without significant differences, all techniques have nearly an equal rate of complications e.g. flap vascular compromise on the short term and loss of projection on the long term [11].

\section{Ideal Nipple Areola Complex (NAC)}

\section{- Height and diameter:}

In a morphologic study of nipple-areola complex in 600 breasts, Sanuki et al. analyzed the results statistically to come up with the findings shown in Table 1. They also found that the mean diameter of the areola in women who gave birth was $0.5 \mathrm{~cm}$ larger than that of those who did not. They classified the sample according to the relation between nipple height and diameter as shown in Table 2 [12].

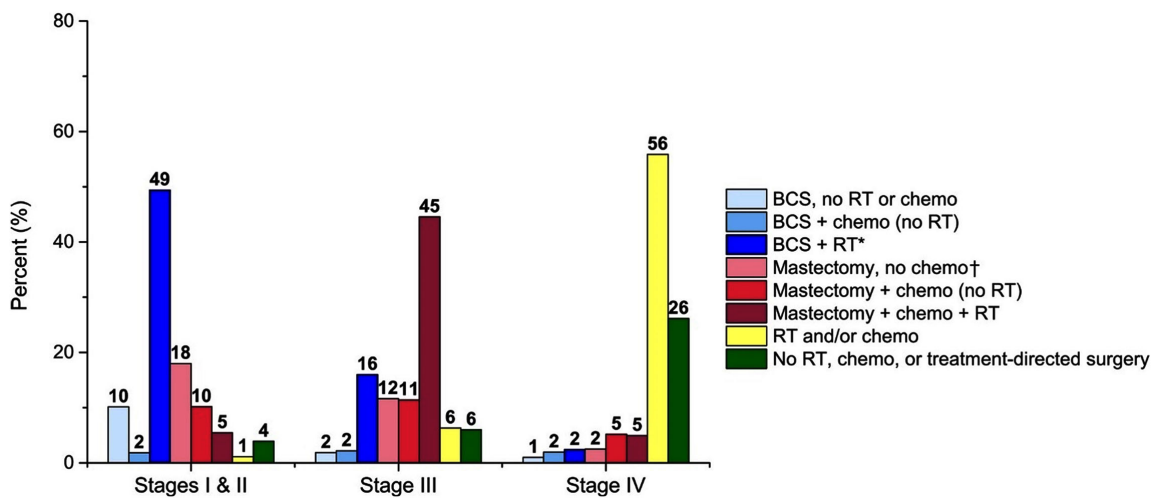

Figure 1. Female Breast Cancer Treatment Patterns (\%) by Stage, 2016. ${ }^{\star}$ A small number of these patients received chemotherapy. $\dagger A$ small number of these patients received radiation therapy (RT). BCS indicates breast-conserving surgery; chemo, chemotherapy (includes targeted therapy and immunotherapy) [2].

Table 1. Diameter of the nipple-areola complex and height of the nipple found by Sanuki et al. [12].

\begin{tabular}{cccc}
\hline & Mean & Range (Max - Min) & Standard Deviation $(\mathrm{cm})$ \\
\hline Diameter of areola & 4.0 & $(7.0-2.0)$ & 1.0 \\
Diameter of nipple & 1.3 & $(2.3-0.6)$ & 0.3 \\
Height of nipple & 0.9 & $(2.0-0)$ & 0.3 \\
\hline
\end{tabular}


Table 2. Classification of nipple shape according to the relation between nipple height and diameter found by Sanuki et al. [12].

\begin{tabular}{|c|c|c|c|}
\hline Finding & Classification & $\begin{array}{c}\text { Relation between } \\
\text { Diameter }(d) \text { and Height }(h)\end{array}$ & $\begin{array}{c}600 \text { Breasts } \\
(\%)\end{array}$ \\
\hline & Is & $\mathrm{d} \leq \mathrm{h}$ & $39(6.5 \%)$ \\
\hline & I sp & $\begin{array}{l}\quad \mathrm{d} \leq \mathrm{h} \\
+ \text { constriction }\end{array}$ & $25(4.2 \%)$ \\
\hline & II s & $\mathrm{d}>\mathrm{h}$ & $361(60.2 \%)$ \\
\hline & II sp & $\begin{array}{c}\mathrm{d}>\mathrm{h} \\
+ \text { constriction }\end{array}$ & $152(25.3 \%)$ \\
\hline & III & Inverted nipple & $21(3.5 \%)$ \\
\hline & IV & Unclassified & $2(0.3 \%)$ \\
\hline
\end{tabular}

\section{- Position:}

The optimal NAC proportions were found by Hauben et al. to be with the proportion of the upper to the lower pole at a ratio of 45:55. The angulation of the nipple was upward at a mean angle of $20^{\circ}$ from the nipple meridian. The areola-breast and nipple-areola proportions were 1:3.4 and 1:3, respectively [13].

Schiffman, with the patient standing or sitting, utilizes a line from the midclavicular point (MC) to the mid-nipple $(\mathrm{N})$. At the same time, a line is marked in the center of the chest wall from the center of the sternum superiorly to the mid-xiphoid process. The inframammary fold is palpated from underneath the breast inferiorly and the tip of the finger palpated superficially and marked on the MC to $\mathrm{N}$ line [10].

Another study by Lewin et al. determined the preferences for the nipple-areola complex on the female breast in our study population. The NAC placement preferred by both genders had a ratio of 40:60x and 50:50y (Figure 2), which means that it was best situated in the middle of the breast gland vertically and slightly lateral to the midpoint horizontally [14].

\section{Geometric Basics}

Circle circumference can be calculated as follows:

$C$ : Circumference, $\pi$ : Pi (22/7), $r$ : Radius, ø: Diameter.

$$
C=2 \pi r=\pi \varnothing=\frac{22 \varnothing}{7} \approx 3 \varnothing
$$

Circle/cylinder circumference nearly equals three times its diameter.

Supposing that a nipple is a cylinder, and my design depends on building that 
cylinder out of three equal vertical flaps, the width of one flap equals $1 / 3$ of its circumference equals the cylinder diameter. To make that possible, the length sides of each one of the three equal flaps should be parallel tangential lines to the circle that forms the cylinder roof (Figure 3 and Figure 4).

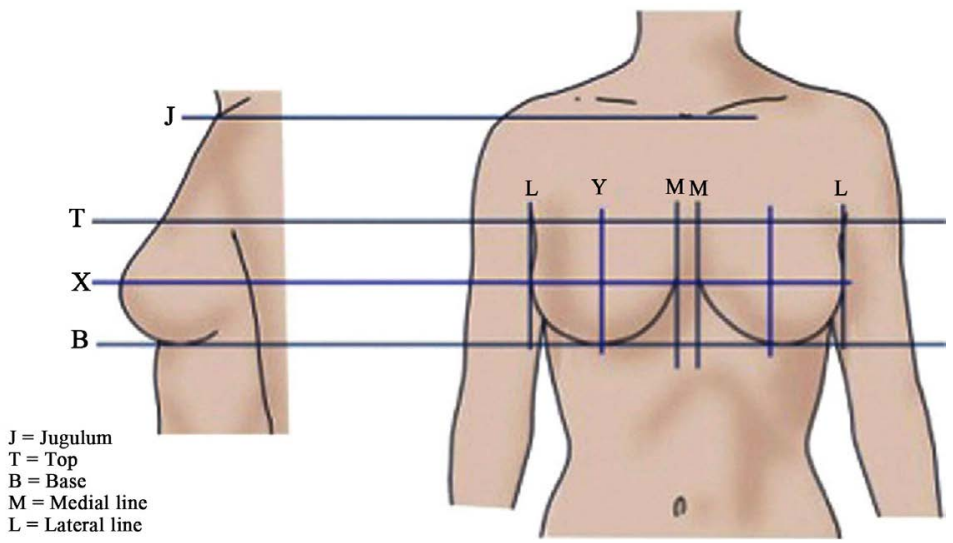

Figure 2. The coordinate system of the breast [14].

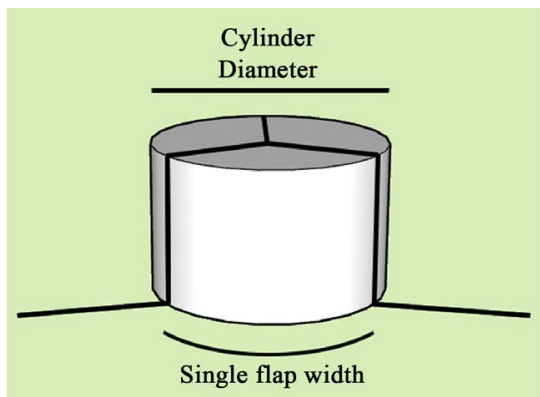

Figure 3. The width of one flap equals $1 / 3$ of its circumference equals the cylinder diameter.

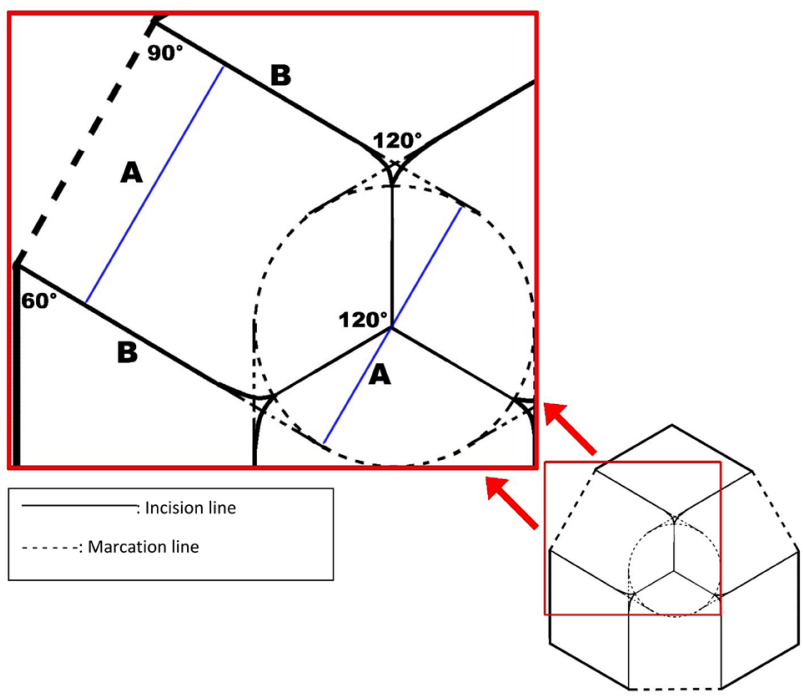

Figure 4. The length sides (B, B) of each one of the three equal flaps should be parallel tangential lines to the circle that forms the cylinder roof. The width of one flap equals the cylinder diameter. 


\section{Advantages}

1) Visually, scars on the areola are three short scars in three different directions and less noticeable than one long scar in the same direction like most of other popular nipple reconstruction flaps.

2) Visually, scars on the areola are three short scars that will never exceed the areola region. After camouflage tattooing, scars will be well-hidden.

3) The design is flexible to be rotated to partially include any previous scars, i.e. mastectomy scar, in the excision diamond shaped area (X).

4) The design is geometry-based, specific, well-detailed (Figure 5 and Figure 6) and flexible to produce a tailored nipple with any desired height and diameter according to guidelines illustrated in ideal nipple areola complex section above.

5) Building the nipple by three random flaps ensures the flaps good vascularity more than most of the popular nipple reconstruction flaps that makes the vascularity of the neo-nipple components depend on one base.

6) Choosing the flaps to be three not more or less is a balance point that has both advantages of preventing flaps vascular compromise, by being not more than three flaps, and defying/redistributing the retraction forces that will oppose the neo-nipple projection, by being not less than three flaps.

7) Projection is held in place by four Polydioxanone sutures that will dissolve after nearly 180 days, the thing that ensures the neo-nipple projection sustainability.

8) The flap design looks like Trillium Grandiflorum flower for having a significant center (pistil) and reciprocating three petals and three sepals (Figure 7).

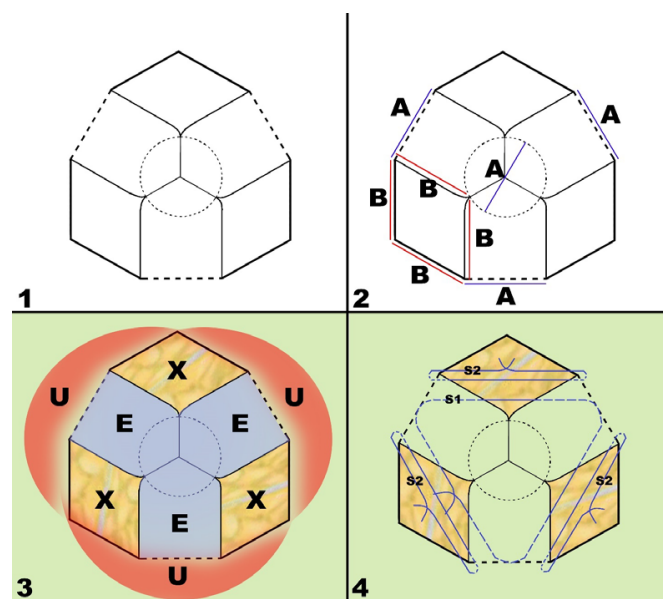

Figure 5. 1. The general flap design. 2: Details regarding the equal sides (A)s or (B)s. A: Neo-nipple diameter, B: Neo-nipple height. 3: The three diamond-shaped skin excision zones (X) (Excision direction to be vertical on sides between (X) and (U) zones and bevelled outwards, from (X), on sides between (X) and (E) zones to ensure that the neo-nipple will look cylidrical not prismatic), The three flap elevations zones (E), The three undermining zones for easy flap mobilization (U). 4: Subcutaneous 3/0 Polydioxanone approximation purse string suture that holds the three flaps bases together (S1) (Approximation is preferred to be done while tracting the tip of each flap vertically upwards), Three 3/0 Polydioxanone sutures that hold base corners of each two adjacent flaps (S2). 


\section{Lookalikes}

Three designs found in the literature can be mixed up with Trillium flap. Differences are shown in Table 3 and Figure 8 below:

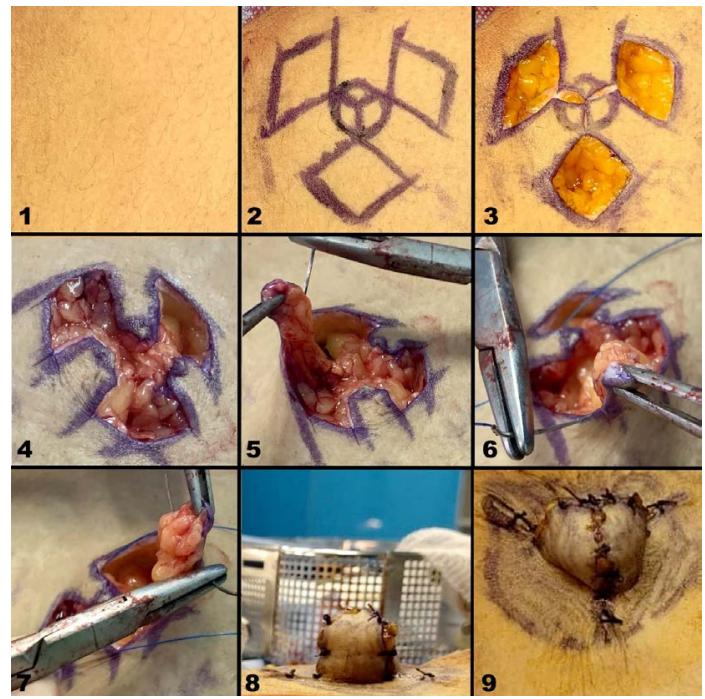

Figure 6. A guide for the main steps of Trillium flap. 8: The neo-nipple projection.

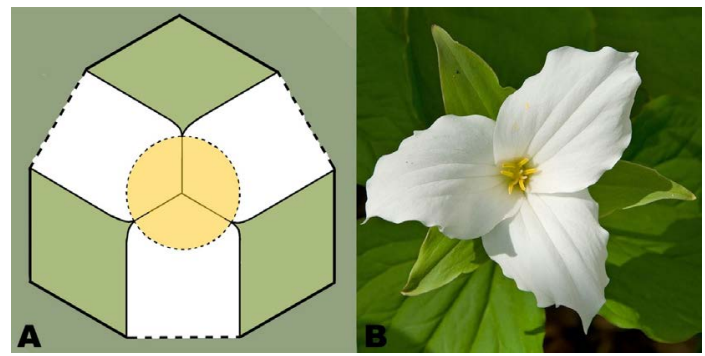

Figure 7. The flap (A) looks like Trillium Grandiflorum flower (B) [15] for having a significant center (pistil) and reciprocating three petals and three sepals.

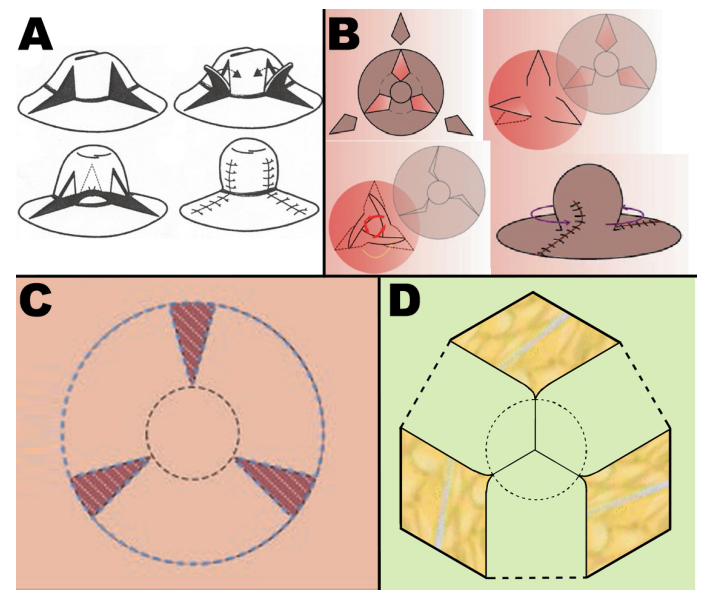

Figure 8. Trillium Flap (D) and its lookalikes (A [10], B [18], C [20]). Essential differences are still there in technique and indications of use. 
Table 3. Trillium Flap and its lookalikes. Essential differences are still there in technique and indications of use.

\begin{tabular}{|c|c|c|c|c|}
\hline & $\begin{array}{l}\text { Huang [16] and } \\
\text { modifications [17] }\end{array}$ & Kim and Singh [18] & Berson [19] & Trillium Flap \\
\hline Purpose & Inverted nipple repair & Inverted nipple repair & Neo-nipple reconstruction & Neo-nipple reconstruction \\
\hline $\begin{array}{l}\text { Main } \\
\text { differences }\end{array}$ & $\begin{array}{l}\text { Three diamond-shaped } \\
\text { flaps to pass through } \\
\text { tunnels under the nipple } \\
\text { while the nipple was } \\
\text { retracted, and the } \\
\text { lactiferous ducts and } \\
\text { fibrous tissue were } \\
\text { transected (Figure } 8(\mathrm{~A}) \text { ). }\end{array}$ & $\begin{array}{l}\text { The elevated dermal flaps are } \\
\text { passed through the tunnels } \\
\text { created and sutured to the } \\
\text { adjacent deepithelialized } \\
\text { dermal region. Design depends } \\
\text { on twisting and locking } \\
\text { principle (Figure } 8(\mathrm{~B}) \text { ). }\end{array}$ & $\begin{array}{l}\text { It may be considered as one of the first } \\
\text { attempts to reconstruct a neo-nipple. } \\
\text { Elevation of three thin split thickness flaps } \\
\text { based on a central undisturbed skin disk. } \\
\text { The three flaps were bunched centrally } \\
\text { creating an umbilicated nipple and leaving } \\
\text { a deepithelialized zone that was allowed to } \\
\text { heal as the areola (Figure } 8(C) \text { ). }\end{array}$ & $\begin{array}{l}\text { - Mainly targets Neo-nipple } \\
\text { reconstruction. } \\
\text { - No dermal flaps tunneled } \\
\text { - No twisting } \\
\text { - Flaps separately depend on } \\
\text { three peripheral bases not } \\
\text { one central base (Figure } \\
\text { (D)). }\end{array}$ \\
\hline
\end{tabular}

\section{Discussion and Conclusion}

Trillium flap is an innovative technique to reconstruct neo-nipple with several advantages that make it superior to other popular flaps. The photos of results included in Figure 6 are for experimental procedures done on excised flaps from abdominoplasties and brachioplasties.

Further application on actual cases is needed with monitoring of neo-nipple projection sustainability on the long term.

\section{Data Availability}

The author confirms that the data supporting the findings of this study are available within the article and its supplementary materials.

\section{Conflicts of Interest}

The authors declare no conflicts of interest regarding the publication of this paper.

\section{References}

[1] Mariotto, A.B., Etzioni, R., Hurlbert, M., Penberthy, L. and Mayer, M. (2017) Estimation of the Number of Women Living with Metastatic Breast Cancer in the United States. Cancer Epidemiology, Biomarkers \& Prevention, 26, 809-815. https://doi.org/10.1158/1055-9965.EPI-16-0889

[2] American College of Surgeons Commission on Cancer (2019) National Cancer Database, 2016 Data Submission. American College of Surgeons Commission on Cancer, Chicago, IL.

[3] Zhao, R., Qiao, Q., Yue, Y., et al. (2003) The Psychological Impact of Mastectomy on Women with Breast Cancer. Chinese Journal of Plastic Surgery, 19, 294-296.

[4] Nozawa, K., Ichimura, M., Oshima, A., et al. (2015) The Present State and Perception of Young Women with Breast Cancer towards Breast Reconstructive Surgery. International Journal of Clinical Oncology, 20, 324-331. https://doi.org/10.1007/s10147-014-0716-0

[5] Gopie, J.P., Mureau, M.A., Seynaeve, C., et al. (2013) Body Image Issues after Bilateral Prophylactic Mastectomy with Breast Reconstruction in Healthy Women at Risk for Hereditary Breast Cancer. Familial Cancer, 12, 479-487. https://doi.org/10.1007/s10689-012-9588-5 
[6] Fallbjörk, U., Rasmussen, B.H., Karlsson, S. and Salander, P. (2013) Aspects of Body Image after Mastectomy Due to Breast Cancer-A Two-Year Follow-up Study. European Journal of Oncology Nursing, 17, 340-345. https://doi.org/10.1016/j.ejon.2012.09.002

[7] Schover, L.R. (1994) Sexuality and Body Image in Younger Women with Breast Cancer. Journal of the National Cancer Institute Monographs, 16, 177-182.

[8] Chen, W., Lv, X., Xu, X., Gao, X. and Wang, B. (2018) Meta-Analysis for Psychological Impact of Breast Reconstruction in Patients with Breast Cancer. Breast Cancer, 25, 464-469. https://doi.org/10.1007/s12282-018-0846-8

[9] Rowland, J.H., Holland, J.C., Chaglassian, T. and Kinne, D. (1993) Psychological Response to Breast Reconstruction. Expectations for and Impact on Postmastectomy Functioning. Psychosomatics, 34, 241-250.

https://doi.org/10.1016/S0033-3182(93)71886-1

[10] Shiffman, M.A. (2018) History of Nipple-Areolar Complex Reconstruction. In: Nipple-Areolar Complex Reconstruction, Springer, Cham, 10-11. https://doi.org/10.1007/978-3-319-60925-6

[11] Davis, G.B., Miller, T. and Lee, G. (2018) Nipple Reconstruction: Risk Factors and Complications. In: Shiffman, M., Ed., Nipple-Areolar Complex Reconstruction, Springer, Cham, 624-625.

[12] Sanuki, J., Fukuma, E. and Uchida, Y. (2009) Morphologic Study of Nipple-Areola Complex in 600 Breasts. Aesthetic Plastic Surgery, 33, 295-297.

https://doi.org/10.1007/s00266-008-9194-y

[13] Hauben, D.J., Adler, N., Silfen, R. and Regev, D. (2003) Breast-Areola-Nipple Proportion. Aesthetic Plastic Surgery, 50, 510-513. https://doi.org/10.1097/01.SAP.0000044145.34573.F0

[14] Lewin, R., Amoroso, M., Plate, N., Clara, C. and Selvaggi, G. (2016) The Aesthetically Ideal Position of the Nipple-Areola Complexon the Breast. Aesthetic Plastic Surgery, 40, 724-732. https://doi.org/10.1007/s00266-016-0684-Z

[15] Ramsey, D. (2007) Trillium grandiflorum. Self-Photographed. Photo Taken at the Mt. Cuba Center Where It Was Identified. https://commons.wikimedia.org/wiki/File:White_Trillium_Trillium_grandiflorum_ Flower_2613px.jpg

[16] Huang, W. (2003) A New Method for Correction of Inverted Nipple with Three Periductal Dermofibrous Flaps. Aesthetic Plastic Surgery, 27, 301-304. https://doi.org/10.1007/s00266-003-3047-5

[17] Hsiao, S., Huang, W., Yu, C., Tsai, Y. and Tung, K. (2008) Refinement of Three Periductal Dermofibrous Flaps Method for Correction of Inverted Nipples.

[18] Kim, J.T. and Singh, J. (2018) Correction of Inverted Nipples with Twisting and Locking Principle. In: Shiffman, M., Ed., Nipple-Areolar Complex Reconstruction, Springer, Cham, 315-329. https://doi.org/10.1007/978-3-319-60925-6_38

[19] Berson, M.I. (1946) Construction of Pseudoareola. Surgery, 20, 808.

[20] Sisti, A., Tassinari, J., Cuomo, R., Brandi, C., Nisi, G., Grimaldi, L. and D’Aniello, C. (2018) Nipple-Areola Complex Reconstruction. In: Shiffman, M., Ed., NippleAreolar Complex Reconstruction, Springer, Cham, 359-368.

https://doi.org/10.1007/978-3-319-60925-6_43 